\title{
Artroplastia total na lesão complexa do cotovelo
}

\section{Total Arthroplasty in Complex Elbow Injury}

\author{
Ricardo Fernandes Rezende ${ }^{10}$ Marcela de Melo Gajo ${ }^{10}$ Sérgio Moreira da Costa ${ }^{10}$ \\ Rafael Fuchs Lazarini $^{10}$ Antonio Enéas Rangel de Carvalho Junior ${ }^{1(1)}$ Ildeu Afonso de Almeida Filho ${ }^{1(1)}$ \\ ${ }^{1}$ Hospital Felício Rocho, Belo Horizonte, MG, Brasil \\ Rev Bras Ortop \\ Endereço para correspondência Ricardo Fernandes Rezende, MD, \\ Rua Ouro Preto, número 715, apartamento 302, Bairro Barro Preto, \\ Belo Horizonte, MG, 30.170-040, Brasil \\ (e-mail: ricardomed1992@gmail.com).
}

\section{Resumo \\ Palavras-chave \\ - articulação do cotovelo \\ - artroplastia de substituição \\ - fraturas do cotovelo \\ - prótese de cotovelo}

Os autores apresentam um caso atípico de fratura complexa do cotovelo esquerdo com perda extensa de tecido ósseo e muscular. O paciente foi submetido a diversos procedimentos cirúrgicos, que resultaram em uma artroplastia total do cotovelo esquerdo associada à reconstrução do tríceps com enxerto do tendão do músculo semitendíneo.

The authors present an atypical case of a left elbow complex fracture with extensive loss of bone and muscle tissue. The patient was submitted to several surgical procedures, which resulted in a total arthroplasty of the left elbow with triceps reconstruction using a semitendinosus muscle tendon graft.

\section{Introdução}

A fratura complexa do cotovelo causada por trauma de alta energia envolve não somente a lesão óssea, mas também o acometimento de tecido nervoso, vascular e muscular. Dessa forma, essas fraturas são consideradas de manejo desafiador, com abordagem escassa na literatura e com necessidade de atuação conjunta de profissionais de várias especialidades. Trata-se de um tipo de lesão com grande impacto na qualidade de vida, devendo ser priorizada a funcionalidade do membro. ${ }^{1}$

recebido

06 de Julho de 2020

aceito

14 de Outubro de 2020
DOI https://doi.org/

10.1055/s-0040-1722574.

ISSN 0102-3616.
A artroplastia do cotovelo, como alternativa terapêutica, torna-se uma opção válida a ser considerada nesses casos de alta complexidade, apesar da sabida necessidade de futura cirurgia de revisão, representando uma possibilidade de salvamento do membro ao invés da amputação, que figurava como uma opção frequente no passado. ${ }^{2}$

No presente relato, ilustramos um caso de lesão complexa constituída de perda da extremidade distal do úmero, bem como da extremidade proximal da ulna juntamente com todo o aparelho extensor. Houve lesão do nervo ulnar, além do comprometimento dos ligamentos colaterais. $\mathrm{O}$
(C) 2021. Sociedade Brasileira de Ortopedia e Traumatologia. All rights reserved.

This is an open access article published by Thieme under the terms of the Creative Commons Attribution-NonDerivative-NonCommercial-License, permitting copying and reproduction so long as the original work is given appropriate credit. Contents may not be used for commercial purposes, or adapted, remixed, transformed or built upon. (https://creativecommons.org/ licenses/by-nc-nd/4.0/)

Thieme Revinter Publicações Ltda., Rua do Matoso 170, Rio de Janeiro, RJ, CEP 20270-135, Brazil 


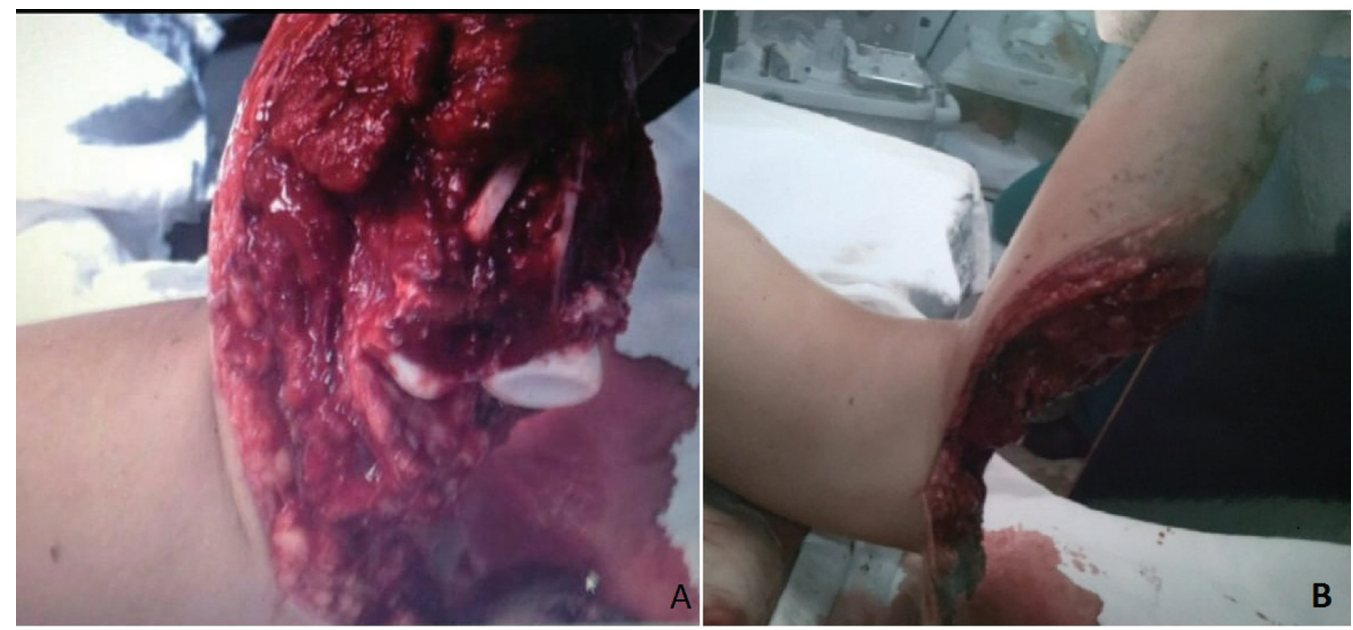

Fig. 1 (A/B) Imagem do cotovelo esquerdo no dia do trauma (pré-operatório).

procedimento realizado consistiu na reconstrução do tríceps com enxerto do tendão do músculo semitendíneo após o paciente ter sido submetido à rotação do retalho do grande dorsal. Foi utilizada uma prótese semiconstrita que resultou em um membro superior funcional.

O paciente assinou devidamente o termo de consentimento livre e esclarecido, concordando e autorizando a divulgação dos dados obtidos em prontuário, bem como as imagens e fotos exibidas neste relato de caso.

\section{Relato de Caso}

O paciente cujo caso é discutido no presente artigo é do sexo masculino, branco, solteiro, tem 18 anos de idade e é motociclista e acadêmico de medicina.
O paciente foi vítima de uma colisão carro-moto na cidade de Natividade, no RJ, no dia 16/12/2015. Recebeu os primeiros atendimentos e imobilização das fraturas pelo corpo de bombeiros no local do acidente, 90 minutos após a colisão. Em seguida, o paciente foi encaminhado ao Hospital São José do Havaí, em Itaperuna.

No primeiro atendimento hospitalar, foi constatada fratura exposta do membro inferior esquerdo e do cotovelo esquerdo, com perda óssea na região distal do úmero e perda do olécrano associada a lesão extensa de pele e músculo e lesão nervosa (-Figura 1).

O paciente evoluiu com choque hemorrágico e hipotermia. Foram realizadas estabilização hemodinâmica e fixação externa transarticular do cotovelo esquerdo; além disso, foi iniciado o uso de Cefazolina (EV), 1g de 6/6 horas, associado à

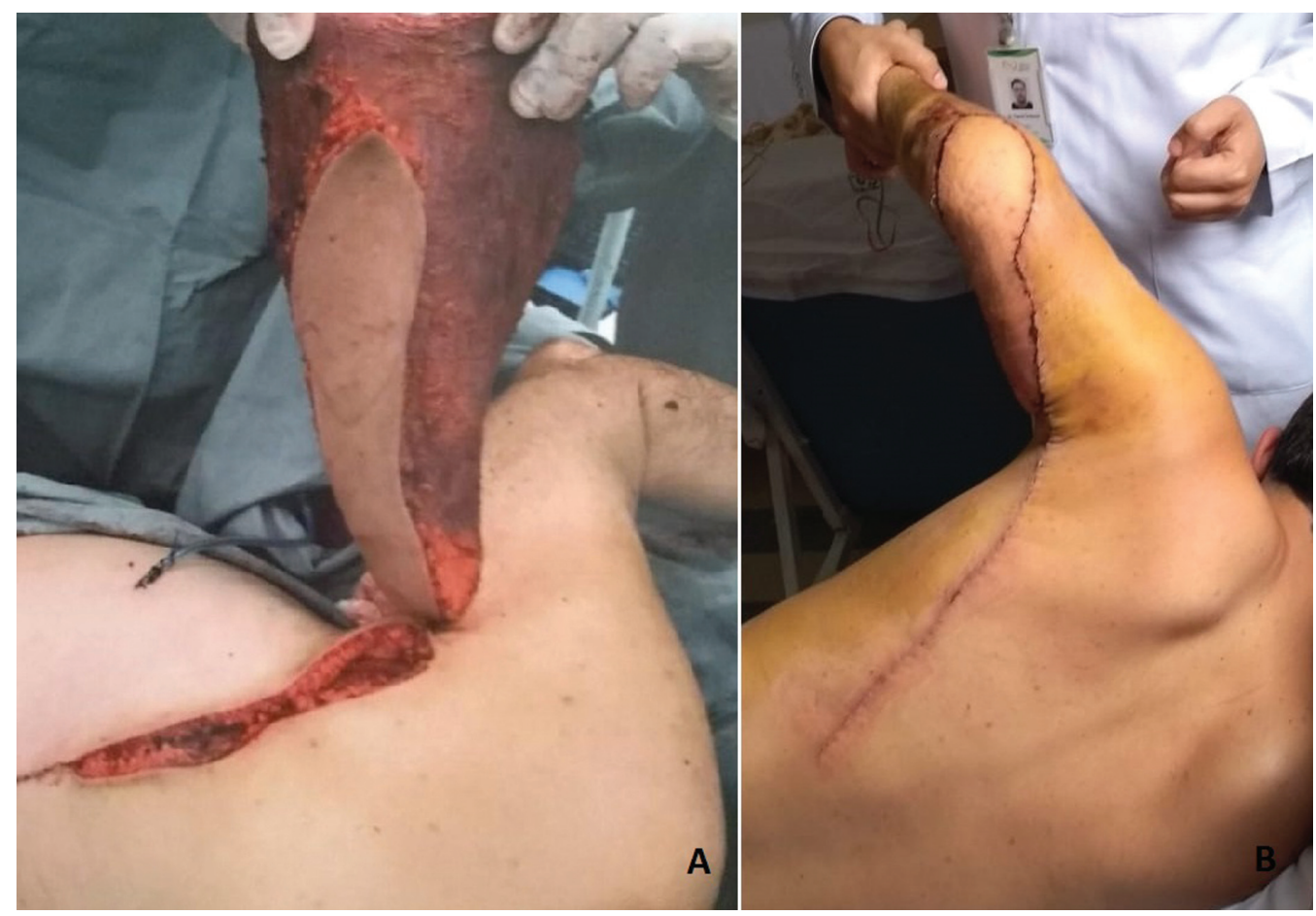

Fig. 2 (A) Peroperatório - retalho do Grande Dorsal. (B) Pós-operatório- retalho do grande dorsal. 


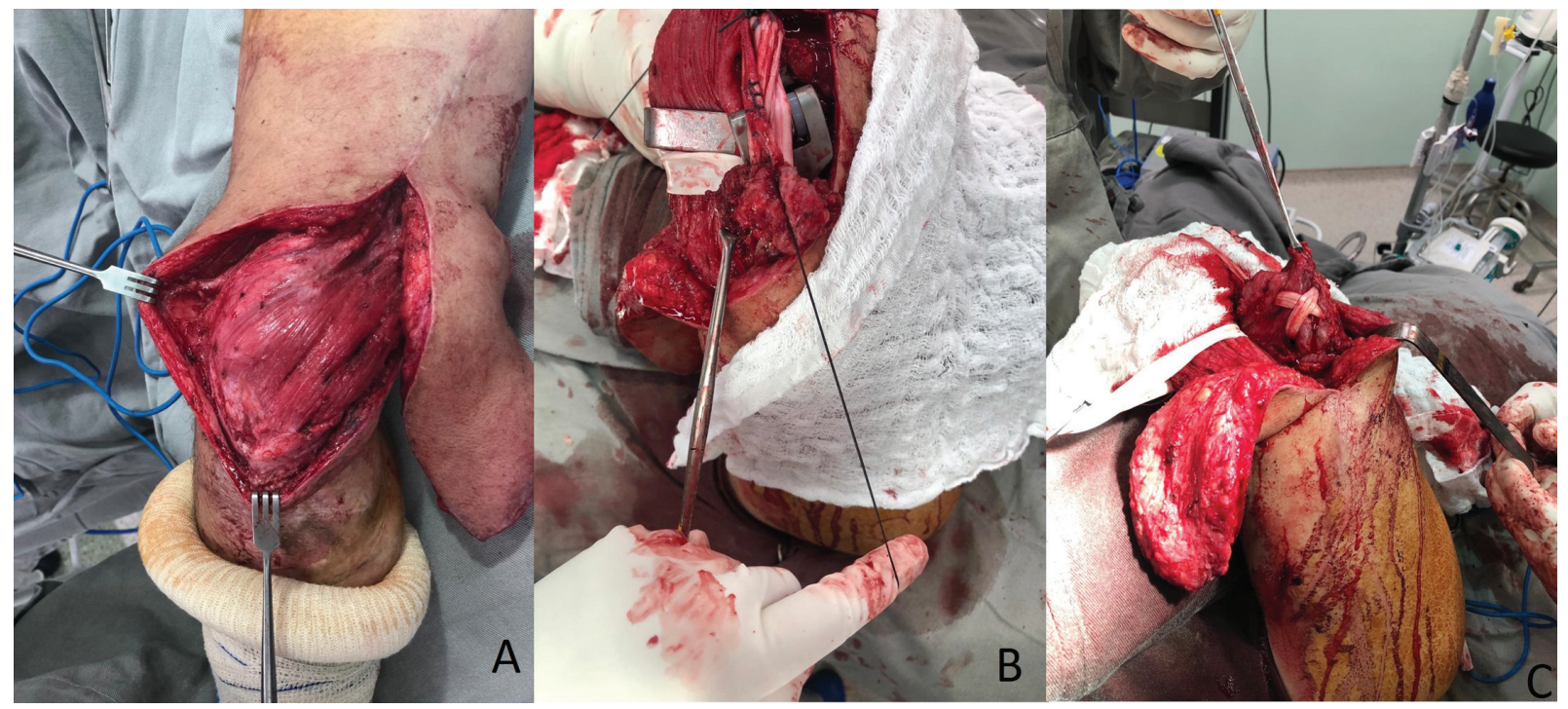

Fig. 3 (A/B/C) Reconstrução do Tríceps com enxerto do semitendíneo.

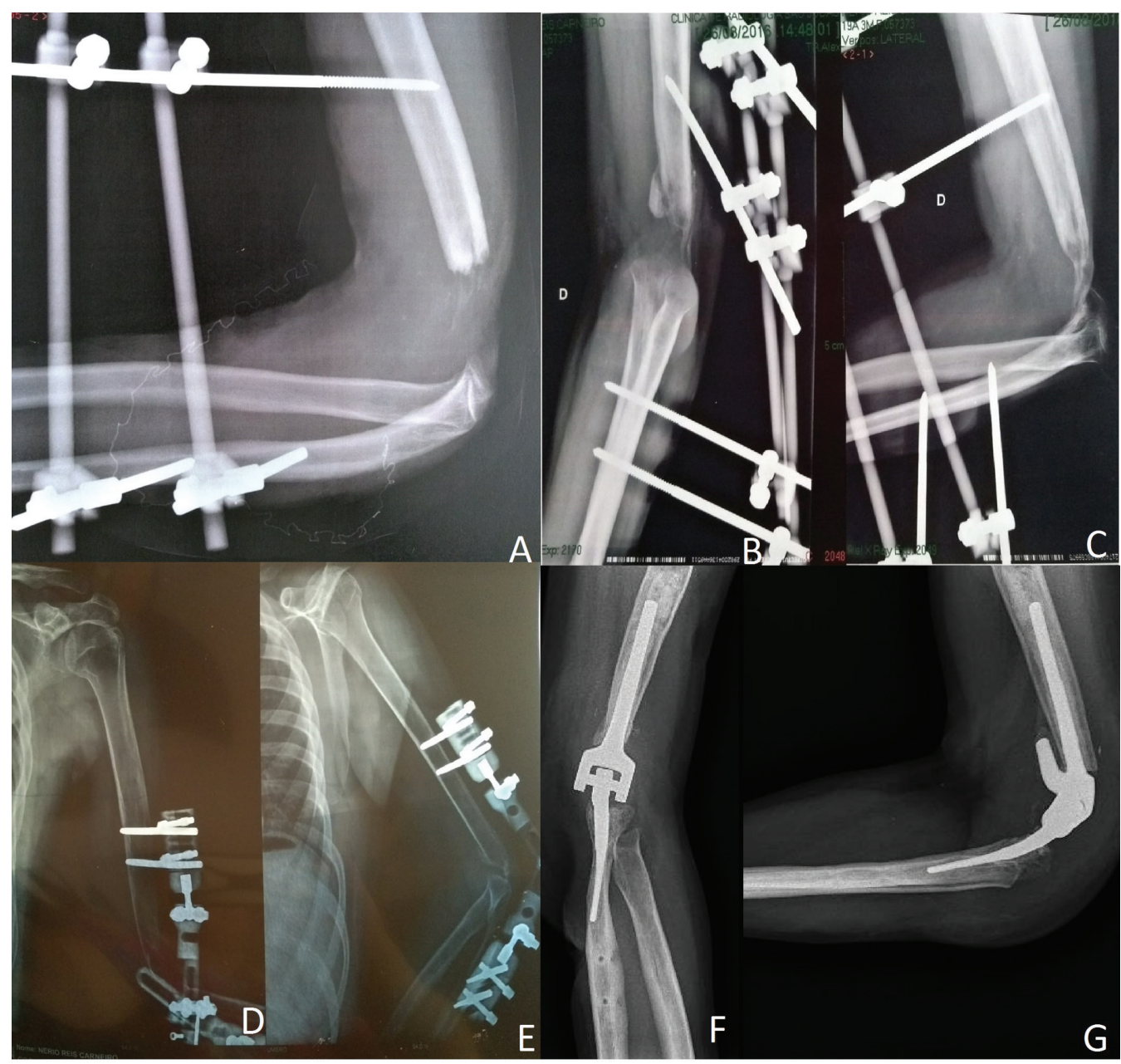

Fig. 4 (A) Radiografia em Perfil mostrando o primeiro fixador externo (tubo-a-tubo transarticular) e falha óssea ao nível do cotovelo esquerdo. $(B / C)$ Radiografia em incidência anteroposterior (AP) e de perfil, respectivamente, mostrando formação de tecido ósseo ao nível do cotovelo esquerdo. (D/E) Radiografia em AP e de perfil mostrando o fixador externo articulado ao nível do cotovelo esquerdo. (F) Radiografia em AP mostrando a prótese de cotovelo. (G) Radiografia em perfil mostrando a prótese de cotovelo. 


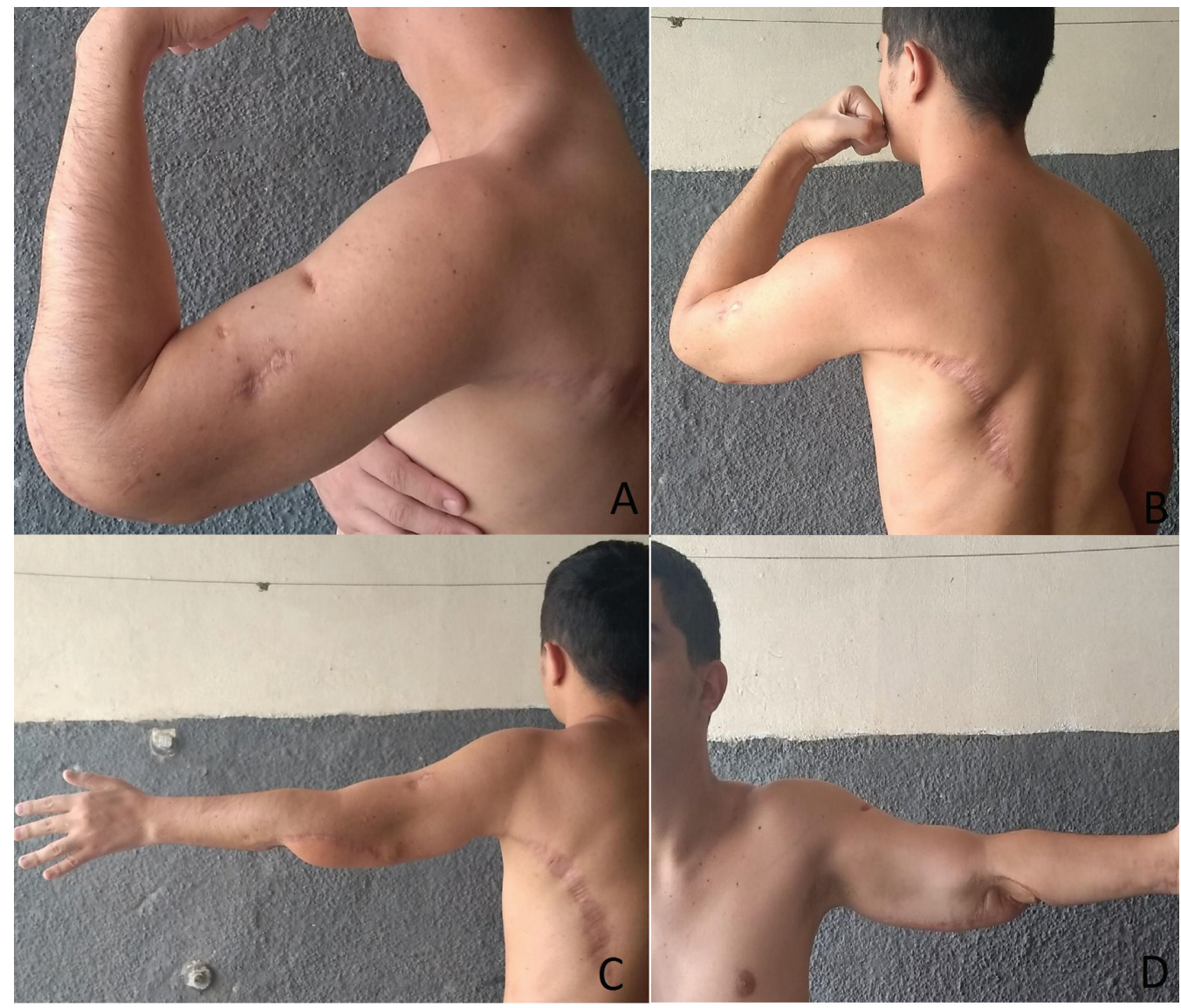

Fig. $5(A / B / C / D)$ Aspecto físico e amplitude de movimento atual do cotovelo esquerdo.

Amicacina, 500g (EV) de 24/24 horas, e o paciente foi encaminhado ao CTI. No dia $17 / 12 / 2015$, o paciente foi submetido a desbridamento cirúrgico do cotovelo, tendo sido suspenso o uso da Cefazolina, que foi substituída pela Ceftriaxona, $1 \mathrm{~g}$ (EV) de 12/12 horas, associada à Amicacina, $500 \mathrm{mg}$ (EV) de 24/24 horas, que foram mantidas até o dia $30 / 12 / 2015$, quando o paciente desenvolveu um quadro de febre, hiperemia cutânea e calor local, sendo prescrita Vancomicina, $500 \mathrm{mg}$ (EV) de 6/6 horas, que foi mantida até o dia $20 / 01 / 2016$. No dia 29/01/2016, o paciente recebeu alta hospitalar.

No dia 29/02/2016, foi realizado enxertia de pele no cotovelo esquerdo, sendo a coxa esquerda a área doadora. 0 paciente foi submetido à terapia com câmara hiperbárica por 6 meses. Em setembro de 2016, foi realizada a troca do fixador externo tubo-a-tubo convencional por um fixador externo articulado, no Hospital Felício Rocho, permitindo ao paciente uma mínima mobilidade articular. Após formação de tecido ósseo, que foi observada na radiografia, este fixador foi retirado, tendo sido adaptado um tutor articulado.

No dia 24/07/2018, foi realizada a rotação do retalho do músculo grande dorsal, pela Equipe de Cirurgia Plástica (-Figura 2). Posteriormente, no dia 18/03/2019 foi realizada a artroplastia total do cotovelo com uma prótese semiconstrita com reconstrução do tríceps utilizando enxerto do tendão do músculo semitendíneo. (-Figuras 3 e 4 )
Após intenso programa de reabilitação, com várias sessões de fisioterapia, hidroterapia e terapia ocupacional, o paciente evoluiu com um membro funcional. Atualmente, o paciente encontra-se satisfeito e sem queixas. Ao exame físico nota-se ausência de sinais flogísticos, sem dor à palpação do cotovelo esquerdo, cicatriz com bom aspecto, amplitude de movimento: extensão de $-20^{\circ}$, flexão de $105^{\circ}$, prono-supinação ativa de $0^{\circ}$, supinação passiva de $90^{\circ}$ e pronação passiva de $30^{\circ}$ (-Figura 5).

\section{Discussão}

A lesão mutilante do membro superior é caracterizada pelo dano significativo aos tecidos moles, vascular, nervoso e ósseo, sendo associada a traumas de alta energia e fraturas complexas. ${ }^{1}$ Este tipo de lesão acomete principalmente indivíduos jovens, do sexo masculino, podendo levar à amputação de parte do membro. ${ }^{2}$

Em casos de lesão traumática complexa, como a relatada, a abordagem inicial determina em grande parte o sucesso do tratamento e a possibilidade de recuperação do membro. A lavagem, desbridamento e antibioticoterapia realizados de maneira precoce, em menos de 24 horas, resultam em menores taxas de infecção e menor índice de falha na cobertura de tecido mole. Apesar da controvérsia sobre o período exato em que essa cobertura deve ser realizada, os retalhos e enxertos precoces apresentam melhor 
prognóstico, podendo muitas vezes serem associados a uma fixação óssea primária. ${ }^{1}$

O uso da prótese apresenta vantagens, tais como uma reabilitação mais rápida, ausência de necessidade de consolidação óssea, ganho de arco de movimento precoce, controle álgico eficiente e recuperação da função do membro. ${ }^{3}$ Apesar disso, ainda apresenta taxa de sobrevida relativamente curta, entre 5 e 10 anos, considerando seu uso em uma população de idade mais avançada e com baixa demanda. ${ }^{2}$

Trata-se de uma prótese que restringe o limite de carga para o membro, mas também apresenta vantagens como a melhora significativa da dor e ganho de função. ${ }^{4}$ No caso descrito, a prótese restabeleceu a conexão entre o braço e o antebraço, transformando um membro balouçante em um membro funcional.

Como contraindicações para a artroplastia total de cotovelo, pode-se citar a presença ativa de infecção; lesões neurológicas associadas, afetando o tríceps e o braquial; ferida aberta de grande comprimento e uma grave perda de funcionalidade da mão. ${ }^{4}$ No caso descrito, o paciente apresentava lesão do tríceps com perda do mecanismo extensor do cotovelo; no entanto, concomitante à artroplastia do cotovelo, foi realizada a reconstrução do tríceps com enxerto do tendão do músculo semitendíneo, restaurando assim o mecanismo extensor do cotovelo.

Apesar dos progressos, ainda há uma taxa significativa de revisão cirúrgica. Em estudos recentes, com seguimento de até 10 anos após a artroplastia, são relatadas taxas de revisão ou necessidade de cirurgia adicional variáveis entre 8 e $27 \%$ dos cotovelos abordados, e taxa de sobrevida do implante de 76 a $92 \%$. 5,6

As complicações mais comuns são a soltura do implante, instabilidade articular e infecção. ${ }^{4}$
Quando optado pela artroplastia de cotovelo como forma de tratamento, o paciente e o médico devem estar cientes das limitações dos implantes, das possíveis complicações e da possibilidade da busca por centros de excelência caso a revisão se mostre necessária. No Brasil, ainda há um pequeno número de casos como o relatado no presente trabalho, sendo assim infrequente a realização de cirurgias de revisão de artroplastia do cotovelo e, portanto, ainda há muito a percorrer nessa curva de aprendizado.

Trabalho desenvolvido no Hospital Felício Rocho, Belo Horizonte, MG, Brasil.

\section{Conflito de Interesses}

Os autores declaram não haver conflito de interesses.

\section{Referências}

1 Miller EA, Iannuzzi NP, Kennedy SA. Management of the Mangled Upper Extremity: A Critical Analysis Review. JBJS Rev 2018;6(04): e11

2 Hall JA. Total Elbow Arthroplasty in the Treatment of Complex Distal Humeral Fractures. In: Biberthaler P, Siebenlist S, Waddell J, eds. Acute Elbow Trauma. Strategies in Fracture Treatments. Cham, Switzerland: Springer; 2019:111-117

3 Harmer LS, Sanchez-Sotelo J. Total Elbow Arthroplasty for Distal Humerus Fractures. Hand Clin 2015;31(04):605-614

4 Levin ES, Plotkin B. Elbow Arthroplasty: From Normal to Failure. Semin Musculoskelet Radiol 2019;23(02):141-150

5 Nestorson J, Rahme H, Adolfsson L. Arthroplasty as primary treatment for distal humeral fractures produces reliable results with regards to revisions and adverse events: a registry-based study. J Shoulder Elbow Surg 2019;28(04):e104-e110

6 Barco R, Streubel PN, Morrey BF, Sanchez-Sotelo J. Total Elbow Arthroplasty for Distal Humeral Fractures: A Ten-Year-Minimum Follow-up Study. J Bone Joint Surg Am 2017;99(18): 1524-1531 